\title{
MODULAÇÃO DE POLÍTICAS PÚBLICAS SANITÁRIAS DO PODER EXECUTIVO PELO SUPREMO TRIBUNAL FEDERAL NO CONTEXTO DO QUADRO PANDÊMICO CAUSADO PELO CORONAVÍRUS (COVID-19): ENFRENTAMENTO DE PARADOXOS
}

\author{
William Paiva Marques Júnior
}

\begin{abstract}
Resumo:
Investiga-se a primariedade do STF na efetividade do Direito Fundamental Social à Saúde, entendido este como direito às prestações estatais positivas tendentes à melhoria da qualidade de vida dos cidadãos, ante o controle de políticas públicas sanitárias adotadas pelo Poder Executivo Federal no contexto do quadro de pandemia do novo Coronavírus. Utiliza-se, como metodologia, de pesquisa do tipo bibliográfica por meio da análise de livros, artigos jurídicos, documentos internacionais, da legislação e da jurisprudência. A pesquisa é pura e de natureza qualitativa, com finalidade descritiva e exploratória.
\end{abstract}

Palavras-chave: modulação; políticas públicas sanitárias; poder executivo; supremo tribunal federal; coronavírus (covid-19)

\section{MODULATION OF PUBLIC HEALTH POLICIES OF EXECUTIVE POWER BY THE SUPREME FEDERAL COURT IN THE CONTEXT OF THE PANDEMIC FRAMEWORK CAUSED BY THE CORONAVIRUS (COVID-19): CONFRONTATION OF PARADOXES}

\begin{abstract}
:
It investigates the primacy of the STF in the effectiveness of the Fundamental Social Right to Health, understood as the right to positive state benefits aimed at improving the quality of life of citizens, under the control of public health policies adopted by the Federal Executive Power in the context of the framework of the new Coronavirus pandemic. As a methodology, bibliographic research is used through the analysis of books, legal articles, international documents, legislation and jurisprudence. The research is pure and of a qualitative nature, with descriptive and exploratory purposes.
\end{abstract}

Keywords: modulation; public health policies; executive power; supreme federal; coronavirus (covid-19)

\section{Introdução}

\footnotetext{
* Doutor e Mestre em Direito Constitucional pela UFC. Professor Adjunto I do Departamento de Direito Privado da Faculdade de Direito da UFC de Direito Civil II (Direito das Obrigações) e Direito Civil V (Direito das Coisas). Coordenador da Graduação em Direito da UFC (2014 a 2017). Assessor do Reitor da UFC. Docente do Programa de Pós-Graduação em Direito da UFC das disciplinas de Metodologia do Ensino Jurídico e Direito das Relações Internacionais e Contemporaneidade. Foi Advogado Júnior da ECT (Empresa Brasileira de Correios e Telégrafos), de 2008 a 2011. E-mail: williamarques.jr@gmail.com .
} 
O trabalho ora desenvolvido aborda a situação da saúde pública no Brasil no contexto das erráticas e tímidas políticas públicas sanitárias adotadas pelo Poder Executivo Federal no contexto do combate aos efeitos deletérios causados pelo quadro pandêmico do novo Coronavírus (Covid-19), e a consequente necessidade de ajuizamento de demandas jurisdicionais para a garantia do cumprimento das disposições constitucionais atinentes à vida, à saúde, afirmando o respeito à dignidade da pessoa humana, com base no paradigma do mínimo existencial.

A problemática enfrentada concentra-se na interferência jurisdicional como um mecanismo útil para viabilizar a efetividade do acesso à saúde e a não exposição do doente em momento de fragilidade à indignidade, em razão da histórica deficiência da prestação do serviço de saúde pública no Brasil diretamente impactada pela pandemia o novo Coronavírus (Covid-19), revelando ausência de planejamento e de correto enfrentamento com muitos paradoxos jurídicos e a quase exaustão do sistema de saúde ante as posturas negacionistas adotadas pelo Presidente Jair Bolsonaro.

Utiliza-se, como metodologia, de pesquisa do tipo bibliográfica por meio da análise de livros, artigos jurídicos, documentos internacionais e da legislação. A pesquisa é pura e de natureza qualitativa, com finalidade descritiva e exploratória.

\section{Características do direito fundamental social à saúde no Brasil à luz do contexto da Constituição Federal de 1988}

Observa-se, a partir de sua análise que a Constituição Federal de 1988 ao consagrar os direitos fundamentais sociais em várias de suas facetas, instituiu um verdadeiro Estado Social de Direito. Os direitos fundamentais sociais têm por escopo a garantia de condições mínimas de vida digna ao cidadão e à coletividade. Nesse diapasão, o $\operatorname{art.~} 1^{\circ}{ }^{\circ}$, incisos III e IV da CF/88 estabelece que a República Federativa do Brasil apresenta como alguns de seus fundamentos a dignidade da pessoa humana e os valores sociais do trabalho, que não serão atingidos caso os direitos sociais venham ser menoscabados pelas políticas públicas.

De forma inovadora no constitucionalismo brasileiro os direitos sociais foram incluídos no rol de direitos fundamentais na Constituição Federal de 1988. De nada adianta a consagração desses direitos se não houver a sua efetividade em nível de justiciabilidade. $O$ papel estatal como agente promotor da justiça social através da erradicação da pobreza e da 


\section{MODULAÇÃO DE POLÍTICAS PÚBLICAS SANITÁRIAS DO PODER EXECUTIVO PELO SUPREMO TRIBUNAL FEDERAL NO CONTEXTO DO QUADRO PANDÊMICO CAUSADO PELO CORONAVÍRUS (COVID-19): ENFRENTAMENTO DE PARADOXOS}

marginalização, bem como da redução das desigualdades sociais e regionais na forma prevista pelo art. $3^{\circ}$-, inciso III da $\mathrm{CF} / 88$ é plasmado mediante a concretização dos direitos fundamentais sociais, em seus mais diversos matizes.

Neste jaez assevera Ingo Wolfgang Sarlet (2006, pág. 73), que apesar da ausência de norma expressa no direito constitucional pátrio qualificando a República brasileira como um Estado Social e Democrático de Direito (o art. $1^{\circ}-$-, caput da $\mathrm{CF} / 88$, refere-se apenas aos termos "democrático" e "Direito"), não restam dúvidas de que nem por isso o princípio fundamental do Estado Social deixou de encontrar guarida na Constituição.

O Estado Social desenvolve-se a partir de políticas públicas inclusivas, na construção efetiva do bem-estar dos seus cidadãos e na consequente supressão das desigualdades no acesso à saúde.

Sob a óptica de Paulo Bonavides (2004, pág. 200), o Estado Social, por sua própria natureza, é um Estado intervencionista, que requer sempre a presença militante do poder político nas esferas sociais, onde cresceu a dependência do indivíduo, pela impossibilidade em que se acha, perante fatores alheios à sua vontade, de prover certas necessidades existenciais mínimas.

Conforme o escólio de Flávia Piovesan (2016, págs. 473 e 474), no rol dos direitos sociais previstos pelo artigo $6^{\circ}$ da Constituição Federal encontra-se o direito à saúde, desdobrado nos artigos 196 a 200, dos quais consta o reconhecimento da saúde como direito de todos e dever do Estado, o acesso universal e igualitário à saúde e a criação do sistema único de saúde, dentre outros aspectos. A Organização Mundial da Saúde (OMS) define saúde como "o completo bem-estar físico, mental e social, e não meramente a ausência de doença ou enfermidade." Nessa conceituação, as relações entre saúde e cidadania ficam destacadas, estendendo-se o campo da saúde para outras esferas, além da exclusivamente biológica, e indicando um alargamento do processo saúde-doença, levando em consideração os determinantes sociais do adoecimento. O Texto Constitucional não traz a definição de saúde, mas sua análise sistemática revela a adequação da definição ora esposada. Ademais, o Brasil é membro da Organização Mundial da Saúde (OMS), aderindo, pois, no âmbito internacional, à definição dada por essa instituição.

Para Enrique González (2006, p. 148), as críticas ao conceito de direito à saúde, de uma perspectiva igualmente compartilhada por várias correntes positivistas e liberais, 
advogam em termos gerais o direito à assistência à saúde - que seria de fato conversível em obrigações positivas e definíveis.

Apesar de a saúde encontrar-se tratada como um direito de todos e de um dever do Estado, consoante a disposição constitucional, estando no rol dos direitos fundamentais sociais, o direito à saúde, no Brasil, encontra-se em estádio bastante distante de sua plena efetivação. Isto porque o poder público tem se mostrado indiferente ao problema da saúde da população, incorrendo em severa omissão o que tipifica um comportamento incompatível com as diretrizes informativas do Texto Constitucional de 1988.

Ante as deficiências no acesso à saúde, os cidadãos acabam tendo a necessidade de ingressar com demandas judiciais, ante a missão institucional do Poder Judiciário de efetivação dos direitos fundamentais.

Os fundamentos axiológicos e constitucionais para a execução de políticas públicas da saúde pelo Poder Judiciário são o respeito à vida e a dignidade da pessoa humana. A sociedade brasileira em geral é vítima da omissão estatal na efetividade do direito à saúde, o que implica no ajuizamento de demandas individuais ou coletivas.

A realidade brasileira, em cotejo com o proposto pela Constituição de 1988 (que consagra o direito à saúde como direito fundamental social e obrigação solidária de todos os entes federativos) demonstra a contradição impeditiva de êxito estatal: ao mesmo tempo em que existe uma extrema centralização política e financeira da União Federal nos programas e nas ações de saúde, observa-se a ausência de diálogo entre os entes federativos revelando uma fragmentação institucional, bem como a exclusão da participação popular nos processos de decisão em matéria de saúde, revelando um déficit democrático nas ações e programas de saúde que não se coadunam com o espírito constitucional.

A ausência de participação cidadã implica na impossibilidade de efetividade do direito fundamental social à saúde. No entanto, destaca-se que a Constituição Federal de 1988 no art. 198, inciso III, garantiu a participação comunitária nas ações e serviços públicos de saúde. Mesmo que se entenda que a participação referenciada seja de índole consultiva, ou seja, não se trate de uma participação plena com poder decisório sobre políticas de saúde, o problema é que ela não se realiza com o alcance desejado pelo legislador constituinte, e, muitas vezes, quando ocorre, serve tão-somente para atribuir uma falsa legitimidade às diretrizes estabelecidas pelos Poderes Executivo e Legislativo. 


\section{MODULAÇÃO DE POLÍTICAS PÚBLICAS SANITÁRIAS DO PODER EXECUTIVO PELO SUPREMO TRIBUNAL FEDERAL NO CONTEXTO DO QUADRO PANDÊMICO CAUSADO PELO CORONAVÍRUS (COVID-19): ENFRENTAMENTO DE PARADOXOS}

À luz do arcabouço constitucional, a engenharia sanitária brasileira é descentralizada entre os entes federativos no atinente às funções de gestão da política de saúde, entretanto, a realidade demonstra um elevado grau de centralização da União nos aspectos de financiamento e formulação das políticas públicas de saúde. Esse descompasso entre o plano idealizado e a realidade prática, com o agravante de problemas nos repasses das verbas públicas para a saúde no Brasil, implicam em sérios problemas de regulação, autonomia, superposição de funções e ausência de coordenação entre os entes da federação.

Apesar da descentralização idealizada normativamente para a política sanitária brasileira, a União que é bastante centralizadora das receitas públicas muitas vezes não dialoga com Estados e Municípios, que apresentam um papel secundário em matéria de políticas públicas de saúde.

A realidade também demonstra que em inúmeras oportunidades, a demora do Poder Judiciário (principalmente o Estadual) acaba por inviabilizar por completo a fruição do direito fundamental à saúde e viola frontalmente a dignidade da pessoa humana, fatores estes ocasionados em razão da omissão estatal na tutela a uma vida com uma dignidade mínima uma vez verificada em diversos casos, a morte do jurisdicionado à espera de uma solução do Poder Público.

$\mathrm{O}$ acesso à justiça na qualidade de garantia assegurada pelo Art. $5^{\circ}$-, inciso XXXV da $\mathrm{CF} / 88$ é o mecanismo propulsor da exigência de cumprimento por parte do Estado dos direitos fundamentais sociais declarados constitucionalmente e que não estão sendo aplicados, possibilitando a exposição das pessoas que se encontrem em situações de indignidade.

A realidade contemporânea brasileira demonstra que o acesso à justiça desempenha papel fundamental no acesso à saúde. Decisões judiciais em temas atinentes ao direito à saúde envolvem questões de alta complexidade, tais como: direito à vida, morte com dignidade e o bem-viver na sociedade.

Para Boaventura de Sousa Santos (2011, pág. 24), muito da litigação que hoje chega aos tribunais deve-se ao desmantelamento do Estado Social (direito laboral, previdência social, educação, saúde, etc). A Suécia, provavelmente detentora do melhor sistema de Estado de bem-estar da Europa tem baixíssima litigação judicial; a Holanda é, também, um dos países com uma das mais baixas taxas de litigação da Europa. O que significa que a litigância 
relaciona-se com culturas jurídicas e políticas, mas também com o nível de efetividade da aplicação dos direitos e com a existência de estruturas administrativas que sustentem essa aplicação.

A judicialização das políticas públicas de saúde no Brasil é um fenômeno mais recente com fortes repercussões sociais que transformou-se em amálgama da função inclusiva do Poder Judiciário no Século XXI.

Sobre as dimensões subjetiva e objetiva do direito fundamental social à saúde, adverte José Joaquim Gomes Canotilho (2006, pág. 477) que estas várias dimensões não devem confundir-se. Ao contrário do que geralmente se afirma, um direito econômico, social e cultural não se dissolve numa mera norma programática ou numa imposição constitucional. Exemplifique-se: o direito à saúde é um direito social, independentemente das imposições constitucionais destinadas a assegurar a sua eficácia (exe.: a criação de um serviço nacional de saúde, geral e tendencialmente gratuito) e das prestações fornecidas pelo Estado para assegurar o mesmo direito (por exemplo, cuidados de medicina preventiva, curativa e de reabilitação).

A passagem do neoliberalismo imanente à década de 1990, década posterior ao declínio da ditadura militar, cedeu espaço às políticas públicas de forte caráter estatal no Século XXI. A realidade processual demonstra que as demandas outrora individuais, hoje apresentam-se como demandas coletivas. Verifica-se que a atuação do Poder Judiciário no neoconstitucionalismo inclusivo consistente em efetivar políticas públicas de direitos sociais pode assumir os mais diversos matizes no tocante ao acesso à saúde. O fortalecimento dos direitos sociais em seus diversos prismas perpassa necessariamente pela proteção aos direitos de grupos minoritários, outrora desamparados das conquistas democráticas surgidas no contexto da $\mathrm{CF} / 88$. O neoconstitucionalismo no Brasil toma por fulcro a hermenêutica constitucional contemporânea (em especial do STF e do STJ) apresenta-se condizente com o modelo de Estado Social de Direito assentado em um modelo que prima pela construção de uma democracia cidadã e inclusiva no acesso à saúde e à tentativa de estabelecimento de uma vida com dignidade.

\section{Ativismo judicial e a missão social do Poder Judiciário como parâmetros de efetividade do acesso às políticas públicas de saúde}

Algumas das mais importantes políticas públicas de saúde adequam-se aos 


\section{MODULAÇÃO DE POLÍTICAS PÚBLICAS SANITÁRIAS DO PODER EXECUTIVO PELO SUPREMO \\ TRIBUNAL FEDERAL NO CONTEXTO DO QUADRO PANDÊMICO CAUSADO PELO CORONAVÍRUS \\ (COVID-19): ENFRENTAMENTO DE PARADOXOS}

seguintes modelos: as ações preventivas ou de atenção primária (que visam, por seu turno, evitar a debilidade da comunidade através do planejamento na sensibilização e capacitação de forma continuada) e ações curativas ou de atenção secundária (tratamento destinado aos doentes, com base em desenvolvimentos científicos e tecnológicos na Medicina). As demandas mais frequentes no Poder Judiciário são aquelas atinentes às ações curativas, de viés secundário.

De acordo com Luís Roberto Barroso (2008, p. 14), a intervenção do Poder Judiciário, mediante determinações à Administração Pública para que forneça gratuitamente medicamentos em uma variedade de hipóteses, procura realizar a promessa constitucional de prestação universalizada do serviço de saúde.

Em casos que envolvam o controle de políticas públicas de saúde o magistrado deve sopesar alguns fatores, tais como o critério da isonomia, a análise orçamentária, bem como a impossibilidade de intromissão contundente nas esferas de competência dos Poderes Executivo e Legislativo. A hermenêutica atinente à proteção dos direitos fundamentais sociais funda-se em princípios específicos. Dentre eles, avulta em importância o postulado do não retrocesso social.

Conforme aduz José Joaquim Gomes Canotilho (2006, págs. 339 e 340), o princípio da proibição de retrocesso social pode formular-se assim: o núcleo essencial dos direitos sociais já realizado e efetivado através de medidas legislativas deve considerar-se constitucionalmente garantido, sendo inconstitucionais quaisquer medidas estaduais que, sem a criação de outros esquemas alternativos ou compensatórios, se traduzam, na prática, numa anulação, revogação ou aniquilação pura e simples desse núcleo essencial. Não se trata, pois, de proibir um retrocesso social captado em termos ideológicos ou formulado em termos gerais ou de garantir em abstrato um status quo social, mas de proteger direitos fundamentais sociais sobretudo no seu núcleo essencial. A liberdade de conformação do legislador e inerente autoreversibilidade têm como limite o núcleo essencial já realizado, sobretudo quando o núcleo essencial se reconduz à garantia do mínimo de existência condigna inerente ao respeito pela dignidade da pessoa humana.

Quando se trata do controle jurisdicional de políticas públicas de saúde deve-se ter em mira a sua máxima efetividade, considerando-se tratar-se de norma de direito fundamental social. Neste jaez eis que a saúde deve ser analisada sob o prisma de sua proteção, respeito e 
plena execução.

Na perspectiva mais hermética e tradicional, a atuação jurisdicional deve obedecer à regra da reserva do possível, vez que não se pode cogitar de gastos estatais sem a contrapartida orçamentária. Nessa análise, a análise jurisdicional deve procurar um ponto de equilíbrio entre a reserva do possível e o mínimo existencial.

Na opinião de Luís Roberto Barroso (2008, p. 20), o Judiciário deverá intervir sempre que um direito fundamental - ou infraconstitucional - estiver sendo descumprido, especialmente se vulnerado o mínimo existencial de qualquer pessoa. Se o legislador tiver feito ponderações e escolhas válidas, à luz das colisões de direitos e de princípios, o Judiciário deverá ser deferente para com elas, em respeito ao princípio democrático.

Averba Ana Paula de Barcellos (2010, p. 812 e 813), que o Judiciário poderá e deverá determinar o fornecimento das prestações de saúde que compõem o mínimo, mas não deverá fazê-lo em relação a outras que estejam fora desse conjunto. Salvo, é claro, quando as opções políticas dos poderes constituídos - afora e além do mínimo - hajam sido judicializadas e tomem a forma de uma lei. Também aqui caberá ao Judiciário dar execução à lei. No caso do mínimo existencial, entretanto, a eficácia decorre diretamente do Texto Constitucional e prescinde da intervenção legislativa. Ou seja: compete ao Judiciário, portanto, determinar o fornecimento do mínimo existencial independentemente de qualquer outra coisa, como decorrência das normas constitucionais sobre a dignidade da pessoa humana e sobre a saúde.

O Supremo Tribunal Federal (STF-ADPF 45 MC / DF, Relator: Min. Celso de Mello, julgamento: 29/04/2004) enfrentou a questão da execução jurisdicional de políticas públicas de saúde e consignou que a realização dos direitos fundamentais sociais, para além de caracterizar-se pela gradualidade de seu processo de concretização - depende, em grande medida, de um inescapável vínculo financeiro subordinado às possibilidades orçamentárias do Estado, de tal modo que, comprovada, objetivamente, a incapacidade econômico-financeira da pessoa estatal, desta não se poderá razoavelmente exigir, considerada a limitação material referida, a imediata efetivação do comando fundado no texto da Carta Política.

Para Luís Roberto Barroso (2008, p. 29) no contexto da análise econômica do direito, costuma-se objetar que o benefício auferido pela população com a distribuição de medicamentos é significativamente menor que aquele que seria obtido caso os mesmos 


\section{MODULAÇÃO DE POLÍTICAS PÚBLICAS SANITÁRIAS DO PODER EXECUTIVO PELO SUPREMO \\ TRIBUNAL FEDERAL NO CONTEXTO DO QUADRO PANDÊMICO CAUSADO PELO CORONAVÍRUS \\ (COVID-19): ENFRENTAMENTO DE PARADOXOS}

recursos fossem investidos em outras políticas de saúde pública, como é o caso, por exemplo, das políticas de saneamento básico e de construção de redes de água potável, que evitariam a ocorrência de diversas doenças.

A construção e a posterior execução de políticas públicas são primordiais para a efetividade do direito à saúde. A redação do artigo 196 da Constituição Federal estabelece que a saúde seja garantida por meio de políticas sociais e econômicas.

As políticas de saúde pública plasmam-se como planos, metas, diretrizes e ações que a Administração Pública estabelece em atendimento aos anseios da população em matéria de saúde. Um dos maiores exemplos de política pública de saúde na experiência brasileira é o Sistema Único de Saúde (SUS), criado em 1988.

As políticas públicas em matéria de saúde no Brasil devem orientar-se com base nos postulados da universalidade; equidade no acesso às prestações e serviços; descentralização, com direção única em cada esfera de governo; atendimento integral, com prioridade para as atividades preventivas, sem prejuízo dos serviços assistenciais e a participação da comunidade.

O SUS apresenta alguns avanços notórios, mesmo ante as mais variadas dificuldades vivenciadas. Ele é hoje reconhecido como a política de maior inclusão social implementada no Brasil e representa um dos elos de manutenção dos compromissos do Estado brasileiro com seus cidadãos. A mudança de paradigma representada pelo SUS é bastante significativa. Este alterou simultaneamente a trajetória da formação do Estado brasileiro, até então de feição neoliberal, com uma lógica fundada na centralização administrativa, e a concepção prévia de controle e regulação da cidadania, assentada sobre a vinculação entre os direitos fundamentais sociais e inserção no mercado formal de trabalho, fenômeno que remonta ao populismo de Vargas na década de 1930.

A análise do SUS demonstra que, embora diversas características do modelo anterior tenham permanecido quase sem nenhuma alteração, tais como: a articulação "público versus privado" na provisão de serviços; a natureza do contrato de trabalho da maioria dos médicos que prestam serviços ao setor público; a insuficiente regulamentação do setor de saúde suplementar até 2000, com a edição da Lei $n^{\circ} .: 9.961 / 2000$-, a realidade é que, ainda assim, o Brasil substituiu um modelo de assistência à saúde baseado no princípio contributivo e centralizado por um modelo em que o direito legal de acesso gratuito às ações e aos serviços 
de saúde em todos os níveis de complexidade é universal e no qual a prestação de serviços está organizada de modo hierarquizado e descentralizado.

Constata-se que é necessária uma reconstrução das políticas públicas brasileiras em matéria de acesso à saúde. Por outro lado, faz-se premente que as constantes interferências do Poder Judiciário ocorram à luz de critérios técnicos e objetivos. Esses parâmetros deverão ponderar uma série de fatores essenciais à realização da justiça, tais como: proporcionalidade; atendimento às listas de medicamentos adotadas pelos entes federativos, otimização dos recursos orçamentários, análise global e não meramente individual do problema enfrentado.

Conforme aduz Ana Paula de Barcellos (2010, p. 807), é certamente penoso para um magistrado negar, por exemplo, o transplante ou o medicamento importado que poderá salvar a vida do autor da demanda, pelo fato de tais prestações não estarem compreendidas no mínimo existencial que decorre da Constituição nem constarem de qualquer outra norma jurídica ou de uma opção política adicional veiculada pelo Legislativo ou pelo Executivo. Nesse contexto, as impressões psicológicas e sociais do magistrado, a quem cabe afinal aplicar a Constituição, não podem ser desconsideradas. Um doente com rosto, identidade, presença física e história pessoal, solicitando ao Juízo uma prestação de saúde, é percebido de forma inteiramente diversa da abstração etérea do orçamento e das necessidades do restante da população, que não são visíveis naquele momento e têm sua percepção distorcida pela incredulidade do magistrado, ou ao menos pela fundada dúvida de que os recursos públicos estejam sendo efetivamente utilizados na promoção da saúde básica.

A falta de eficiência do Legislativo e do Executivo é um dos motivos determinantes do ativismo judicial, considerando que a solução mais atenta à efetividade do Texto Constitucional, funda-se na urgência ao atendimento judicial nas situações que envolvam a efetividade de políticas públicas sanitárias.

\section{Modulação de políticas públicas sanitárias do Poder Executivo pelo STF no contexto do quadro pandêmico causado pelo novo Coronavírus (Covid-19): enfrentamento de paradoxos}

O histórico do Coronavírus, de acordo com a Organização Pan-Americana da Saúde (OPAS, 2020, online), se deu conforme o seguinte percurso: (1) em 31 de dezembro de 2019, a Organização Mundial da Saúde (OMS) foi alertada sobre vários casos de pneumonia na cidade de Wuhan, província de Hubei, na China. Tratava-se de uma nova cepa (tipo) de 


\section{MODULAÇÃO DE POLÍTICAS PÚBLICAS SANITÁRIAS DO PODER EXECUTIVO PELO SUPREMO TRIBUNAL FEDERAL NO CONTEXTO DO QUADRO PANDÊMICO CAUSADO PELO CORONAVÍRUS (COVID-19): ENFRENTAMENTO DE PARADOXOS}

coronavírus que não havia sido identificada antes em seres humanos. (2) Uma semana depois, em 7 de janeiro de 2020, as autoridades chinesas confirmaram que haviam identificado um novo tipo de coronavírus. Os coronavírus estão por toda parte. Eles são a segunda principal causa de resfriado comum (após rinovírus) e, até as últimas décadas, raramente causavam doenças mais graves em humanos do que o resfriado comum. (3) Ao todo, sete coronavírus humanos (HCoVs) já foram identificados: HCoV-229E, HCoV-OC43, HCoV-NL63, HCoVHKU1, SARS-COV (que causa síndrome respiratória aguda grave), MERS-COV (que causa síndrome respiratória do Oriente Médio) e o, mais recente, novo coronavírus (que no início foi temporariamente nomeado 2019-nCoV e, em 11 de fevereiro de 2020, recebeu o nome de SARS-CoV-2). Esse novo coronavírus é responsável por causar a doença COVID-19. (4) Em 30 de janeiro de 2020, a OMS declarou que o surto do novo coronavírus constitui uma Emergência de Saúde Pública de Importância Internacional (ESPII) - o mais alto nível de alerta da Organização, conforme previsto no Regulamento Sanitário Internacional. Essa decisão buscou aprimorar a coordenação, a cooperação e a solidariedade global para interromper a propagação do vírus. Essa decisão aprimora a coordenação, a cooperação e a solidariedade global para interromper a propagação do vírus.

Conforme dados divulgados pela OPAS (2020, online), a OMS declarou, em 30 de janeiro de 2020, que o surto da doença causada pelo novo Coronavírus (COVID-19) constitui uma Emergência de Saúde Pública de Importância Internacional - o mais alto nível de alerta da Organização, conforme previsto no Regulamento Sanitário Internacional. Em 11 de março de 2020, a COVID-19 foi caracterizada pela OMS como uma pandemia. Até 20 de abril de 2020, foram confirmados no mundo 2.314.621 casos de COVID-19 (72.846 novos em relação ao dia anterior) e 157.847 mortes (5.296 novas em relação ao dia anterior). Nesse contexto, o Brasil confirmou 40.581 casos e 2.845 óbitos até a tarde do dia 20 de abril de 2020, afora os casos não detectados. As medidas de proteção são as mesmas utilizadas para prevenir doenças respiratórias.

Em 01 de maio de 2020, conforme dados divulgados pelo Ministério da Saúde (2020, online), o Brasil confirmou 91.589 casos e 6.329 óbitos, com uma taxa de letalidade, que indica o número de mortos entre pacientes infectados, de 6,9\%, uma das mais altas do mundo.

Consoante esposado por Amartya Sen (2011, págs. 319 e 320), é razoável sustentar que as decisões sobre saúde pública com muita frequência respondem 
inadequadamente ao sofrimento real dos pacientes e à experiência de cura. Por outro lado, na avaliação desse debate, presente tanto nas discussões passadas como nas contemporâneas, as extensas limitações da perspectiva interna também devem ser consideradas. Mesmo que para a avaliação sensorial a prioridade da visão interna dificilmente possa ser contestada, a prática médica não se ocupa exclusivamente da dimensão sensorial da má saúde, por mais importante que seja. Um problema da dependência da própria opinião do paciente sobre assuntos médicos reside no fato de que a visão interna do paciente pode estar seriamente limitada por seu conhecimento e experiência social. Uma pessoa criada em uma comunidade com um grande número de doenças ou poucas instalações médicas tende a considerar alguns sintomas como "normais" mesmo quando são clinicamente evitáveis. Como os desejos e os prazeres adaptativos, há aqui também uma questão de adaptação às circunstâncias sociais, com consequências bastante obscuras.

No Brasil, existe uma gleba de consequências da pandemia para o direito público no Brasil decorrentes, sobretudo: (1) do surgimento de um corpo normativo específico para o enfrentamento desta calamidade pública, criando um verdadeiro regime jurídico balizador de assuntos desafiadores para a Administração Pública no contexto das transformações da Covid19; (2) do eventual conflito entre, de um lado, as medidas propugnadas para a prevenção do contágio e, de outro, direitos fundamentais individuais e direitos da personalidade; e (3) das repercussões desta crise para o regime jurídico-administrativo dos serviços públicos, setores de infraestrutura e seus eventuais prestadores privados.

O subsistema normativo brasileiro concebido para enfrentar a pandemia do coronavírus tem origem na Portaria $\mathrm{n}^{\circ} .: 188$ do Ministério da Saúde, de 3 de fevereiro de 2020, responsável pela declaração de emergência em saúde pública de importância nacional (nos termos do Decreto $\mathrm{n}^{\mathrm{o}}$ 7.616/11). O regulamento ministerial buscou, inicialmente, emitir orientações às autoridades de saúde e sanitárias para a contenção da epidemia, por meio do estabelecimento do Centro de Operações de Emergências em Saúde Pública (COE-nCoV) como mecanismo nacional da gestão coordenada da resposta à emergência no âmbito nacional.

O disciplinamento normativo das medidas combativas ao Coronavírus surge a partir da proteção aos direitos fundamentais sociais, especialmente a necessidade de criação de sistemas de proteção à saúde. Na visão de Luigi Ferrajoli (2009, p. 115), também os 


\section{MODULAÇÃO DE POLÍTICAS PÚBLICAS SANITÁRIAS DO PODER EXECUTIVO PELO SUPREMO \\ TRIBUNAL FEDERAL NO CONTEXTO DO QUADRO PANDÊMICO CAUSADO PELO CORONAVÍRUS \\ (COVID-19): ENFRENTAMENTO DE PARADOXOS}

direitos sociais, como os direitos à saúde e ao meio ambiente, exigem limites e proibições de lesões.

Lamentavelmente, as previsões de que o coronavírus pode causar um impacto negativo enorme no problemático Sistema Único de Saúde (SUS) já se materializaram na asfixia ao atendimento dos usuários com milhares de mortos e a ausência de leitos nos municípios mais atingidos.

Logo após a declaração de emergência, em 6 de fevereiro de 2020, foi sancionada a Lei $\mathrm{n}^{\circ} 13.979$ (a Lei do Coronavírus, que, por força de seu artigo $7^{\circ}$, foi posteriormente regulada pela Portaria n 356 do Ministério da Saúde, de 11 de março de 2020 que declara, em todo o território nacional, o estado de transmissão comunitária do coronavírus), a qual prevê dentre as medidas relacionadas ao combate do surto de Covid-19: (1) determinação de isolamentos, quarentenas, exames e testes compulsórios ou a restrição excepcional e temporária, conforme recomendação técnica e fundamentada da Agência Nacional de Vigilância Sanitária, por rodovias, portos ou aeroportos de entrada e saída do País; e locomoção interestadual e intermunicipal; (2) dispensa de licitação para aquisição de bens e serviços destinados ao enfrentamento da emergência e a autorização para requisição de bens e serviços de pessoas naturais e jurídicas (notadamente de hospitais privados, sem a necessidade de celebração de contrato administrativo, e profissionais de saúde, sem a formação de vínculos empregatícios), assegurada a justa indenização; e (3) obrigatoriedade do compartilhamento entre órgãos e entidades da administração pública federal, estadual, distrital e municipal de dados essenciais à identificação de pessoas infectadas ou com suspeita de infecção pela Covid-19, com a finalidade exclusiva de evitar a sua propagação., caso demandado por autoridade sanitária, devendo haver a atualização de dados pelo Ministério da Saúde.

Afora a legislação federal, deve-se ressaltar ainda que, após a declaração oficial da pandemia de coronavírus pela Organização Mundial da Saúde (OMS), em 11 de março, uma série de decretos estaduais (e até mesmo municipais) se somou ao regramento federal existindo algumas normatizações mais flexíveis e outras mais restritivas.

A situação brasileira é peculiar no contexto mundial considerando a posição negacionista assumida pelo Presidente da República, Jair Bolsonaro. Esse posicionamento gerou uma série de conflitos com o então Ministro da Saúde, Luiz Henrique Mandetta que 
estava assumindo uma postura pública extremamente alinhada às políticas desenvolvidas na China, nos Estados Unidos e nos países europeus, que adotaram o isolamento e quarentena como medidas efetivas para o enfrentamento da emergência de saúde pública, gerando uma série de cizânias na política e na sociedade.

Esses confrontos acabam por ser apreciados pelo Supremo Tribunal Federal, atuando como modulador dos radicalismos e conflitos fomentados pelo Poder Executivo. Nessa órbita de ideias, destaca-se a recomendação de Michael J. Sandel (2012, pág. 16): “Em tempos de dificuldades, uma boa sociedade se mantém unida. Em vez de fazer pressão para obter mais vantagens, as pessoas tentam se ajudar mutuamente."

O radicalismo negacionista do Presidente implica em comportamento errático no enfrentamento à Covid-19. Inicialmente menosprezou a doença, qualificando-a como "gripezinha" e estimulou aglomerações nas ruas. No momento subsequente, passou a abraçar uma nova panaceia, qual seja, a utilização do medicamento cloroquina, ainda sem comprovação científica efetiva no combate em larga escala ao Coronavírus.

Entre o puro negacionismo e a ciência, esta deve prevalecer. Sobre o poder científico nas políticas públicas, aduz Amartya Sen (2010, pág. 210): “O importante neste momento é fazer com que as políticas e os programas utilizem as lições que emergiram das investigações analíticas e dos estudos empíricos.”

Em idêntico sentido, Rubens Ricupero (2017, pág. 735), entende que o poder efetivo brota da aquisição do conhecimento pela educação e a pesquisa, de sua aplicação à vida material, da capacidade de lidar com a totalidade dos desafios, da conquista de nível comparável ao dos avançados, não apenas em isolados setores de excelência, mas em todos os setores da sociedade brasileira, a começar pelo ambiental, os direitos humanos, a igualdade de gênero, social, racial, a proteção dos membros mais frágeis e vulneráveis da comunidade.

O Chefe do Poder Executivo, no afã de flexibilizar a quarentena para a reabertura de atividades econômicas, na contramão das orientações da Organização Mundial da Saúde (OMS) e do Ministério da Saúde, substituiu injustificadamente o ministro Luiz Henrique Mandetta (que angariou uma aprovação popular bem maior que a do Presidente na condução do combate ao vírus) por Nelson Teich, um médico-empresário sem vivência no SUS, em abril de 2020, por força das divergências quanto à amplitude da política de isolamento social no período. 


\section{MODULAÇÃO DE POLÍTICAS PÚBLICAS SANITÁRIAS DO PODER EXECUTIVO PELO SUPREMO TRIBUNAL FEDERAL NO CONTEXTO DO QUADRO PANDÊMICO CAUSADO PELO CORONAVÍRUS (COVID-19): ENFRENTAMENTO DE PARADOXOS}

Sabe-se que os países nos quais houve seriedade na prática da quarentena ou do isolamento máximo, denominado "lockdown”, essas medidas foram decisivas na preservação das vidas e dos sistemas de saúde, evitando um colapso ainda mais profundo na economia. $\mathrm{O}$ "lockdown" é a maior restrição possível na atuação contra a Covid-19. Esse tipo de recurso já foi adotado em regiões da Itália, Espanha e China, por exemplo. Ressalte-se que, no início de maio de 2020, quatro municípios da Região Metropolitana de São Luís, são os primeiros do país a adotar o "lockdown" , por força de decisão judicial, a partir de ação do Ministério Público do Maranhão, acatada pelas autoridades estaduais e municipais.

No plano empírico, observa-se que o relaxamento nas medidas de isolamento implica em expressivo aumento no número de pessoas infectadas e de mortos por Covid-19, podendo provocar uma catástrofe ainda maior, até mesmo na economia, fato este que resta ignorado pelo Chefe do Poder Executivo Federal.

Desde o início da crise, autoridades do Legislativo, e, especialmente do Judiciário derrubam, acertadamente, decisões equivocadas do presidente da República. Nesse diapasão, tomando como fundamento o disposto nos artigos constitucionais que consagram os direitos à vida, à saúde e à informação da população (art. 5º caput, XIV e XXXIII, art. $6^{\circ}$ e art. 196, $\mathrm{CF} / 88$ ), bem como a incidência dos princípios da prevenção e da precaução (art. 225, CF/88), o ministro relator Luis Roberto Barroso, no julgamento da Medida Cautelar na Arguição de Descumprimento de Preceito Fundamental (ADPF) $n^{\circ} .:$ 669/DF (STF- ADPF 669 MC / DF, Relator: Min. Roberto Barroso, julgamento: 31/03/2020), vaticinou: “...na dúvida quanto à adoção de uma medida sanitária, deve prevalecer a escolha que ofereça proteção mais ampla à saúde." Com esse entendimento, o magistrado concedeu pedido liminar para vedar a produção e circulação, por qualquer meio, de qualquer campanha publicitária promovida pelo Governo Federal que pregue: "O Brasil Não Pode Parar". Para o Relator: "O uso de recursos públicos para tais fins, claramente desassociados do interesse público consistente em salvar vidas, proteger a saúde e preservar a ordem e o funcionamento do sistema de saúde, traduz uma aplicação de recursos públicos que não observa os princípios da legalidade, da moralidade e da eficiência, além de deixar de alocar valores escassos para a medida que é a mais emergencial: salvar vidas (art. 37 , caput e $\left.\S 1^{\circ}, \mathrm{CF}\right)$."

Essa postura intransigente, inconsequente e incongruente do Presidente da República reverberou na construção de intensos embates jurídicos, tendo como protagonista 
na solução das controvérsias, o STF. As cizânias políticas geraram um intenso clima de insegurança no quadro federativo brasileiro, com decisões divergentes entre as diversas esferas de governos.

No julgamento da ADPF $n^{\circ}$ :: 568 /PR em 22/03/2020, o ministro Alexandre de Moraes, do STF, determinou a imediata destinação de R \$ 1,6 bilhão ao Ministério da Saúde para custeio de ações de combate ao novo coronavírus. O ministro homologou proposta de ajuste apresentada pelo procurador-geral da República, em que foi firmado, em 2019, acordo sobre destinação de valores oriundos da Operação Lava-Jato. O acordo firmado entre a PGR, o presidente da Câmara dos Deputados e a União, com a contribuição do presidente do Senado Federal e do procurador-geral da Fazenda Nacional, destinava R\$ 1,6 bilhão à educação e R\$ 1 bilhão para a proteção ao meio ambiente. $\mathrm{O}$ valor agora repassado à pasta da Saúde foi deslocado de ações e projetos ainda não executados na área de Educação, com a anuência das autoridades envolvidas, diante da situação excepcional de calamidade pública decorrente da pandemia. O ministro considerou informações apresentadas nos autos, no sentido de que a realocação solicitada não acarreta descontinuidade de ações ou programas de governo e busca atender a uma necessidade premente "que ameaça a vida e a integridade física dos brasileiros". "A gravidade da emergência causada pela pandemia do Covid-19 exige das autoridades brasileiras, em todos os níveis de governo, a efetivação concreta da proteção à saúde pública, com a adoção de todas as medidas possíveis para o apoio e manutenção das atividades do Sistema Único de Saúde", afirmou o ministro. Na decisão, o ministro Alexandre de Moraes ressalta que a Constituição Federal, em diversos dispositivos, prevê princípios e regras de competência no tocante à proteção da saúde pública. "O direito à vida e a saúde aparecem como consequência imediata da consagração da dignidade da pessoa humana como fundamento da República Federativa do Brasil”, conclui. Conforme diagnóstico do Ministro Alexandre de Moraes: "O desafio que a situação atual coloca à sociedade brasileira e às autoridades públicas é da mais elevada gravidade, e não pode ser minimizado. A pandemia de COVID-19 (Coronavírus) é uma ameaça real e iminente, que irá extenuar a capacidade operacional do sistema público de saúde, com consequências desastrosas para a população, caso não sejam adotadas medidas de efeito imediato.”

Observa-se, no julgado em comento, atendimento à recomendação de Nicola Matteucci (1998, pág. 465) conforme a qual os direitos sociais (direito ao trabalho, à 


\section{MODULAÇÃO DE POLÍTICAS PÚBLICAS SANITÁRIAS DO PODER EXECUTIVO PELO SUPREMO \\ TRIBUNAL FEDERAL NO CONTEXTO DO QUADRO PANDÊMICO CAUSADO PELO CORONAVÍRUS \\ (COVID-19): ENFRENTAMENTO DE PARADOXOS}

assistência, ao estudo, à tutela da saúde, liberdade da miséria e do medo), maturados pelas novas exigências da sociedade industrial, implicam, por seu lado, um comportamento ativo por parte do Estado ao garantir aos cidadãos uma situação de certeza.

O ministro Marco Aurélio, do Supremo Tribunal Federal na Medida Cautelar na ADI $n^{\circ} .: 6.341 / D F$, julgamento: 24/03/2020, deferiu em parte pedido de liminar do PDT na ADI para explicitar que as medidas adotadas pelo Governo Federal na MP n .: 926/2020 para o enfrentamento do novo coronavírus não afastam a competência concorrente nem a tomada de providências normativas e administrativas pelos estados, pelo Distrito Federal e pelos municípios. Na ação, o PDT requereu a suspensão da eficácia de diversos dispositivos da MP $n^{\circ} .: 926 / 202$. No entanto, para o ministro, a norma, diante do quadro de urgência e da necessidade de disciplina, foi editada a fim de mitigar a crise internacional que chegou ao Brasil. Essa parte do pedido foi indeferida. Para o relator, a distribuição de atribuições prevista na MP não contraria a Constituição Federal, pois as providências não afastaram atos a serem praticados pelos demais entes federativos no âmbito da competência comum para legislar sobre saúde pública (artigo 23, inciso II). "Presentes urgência e necessidade de ter-se disciplina geral de abrangência nacional, há de concluir-se que, a tempo e modo, atuou o presidente da República ao editar a Medida Provisória”, concluiu. Conforme análise do julgador, a MP, ante quadro revelador de urgência e necessidade de disciplina, foi editada com a finalidade de mitigar os impactos da crise internacional que chegou ao Brasil. Há de ter-se a visão voltada ao coletivo, ou seja, à saúde pública, mostrando-se interessados todos os cidadãos. $\mathrm{O}$ artigo $3^{\circ}$, caput, remete às atribuições, das autoridades, quanto às medidas a serem implementadas no que concerne à adoção pelas autoridades, no âmbito de suas competências, dentre outras, as medidas de restrição excepcional e temporária, conforme recomendação técnica e fundamentada da Agência Nacional de Vigilância Sanitária, por rodovias, portos ou aeroportos de entrada e saída do País; e locomoção interestadual e intermunicipal. Na visão do relator, não se pode ver transgressão a preceito da Constituição Federal. As providências não afastam atos a serem praticados por Estado, o Distrito Federal e Município considerada a competência concorrente na forma do artigo 23, inciso II, da Lei Maior.

O Plenário do STF (2020, online), por unanimidade, referendou no dia 15/4/2020 a decisão liminar, concedida pelo ministro Marco Aurélio, conforme a qual as competências 
concedidas à Agência Nacional de Vigilância Sanitária (Anvisa) pela MP nº: 926/2020 não afastam a competência concorrente de estados e municípios sobre saúde pública. Assim, as medidas sanitárias que vêm sendo tomadas por governadores passam a ser, em tese, respaldadas pela corte. Para o ministro Gilmar Mendes, a decisão é uma forma de restaurar "positivamente uma política dos governadores, que passam a ter voz nessa sistemática, e isso é constitucional". A maioria dos ministros aderiu à proposta do ministro Edson Fachin sobre a necessidade de que o artigo $3^{\circ}$ da Lei $n^{\circ}:$ 13.979/2020 também seja interpretado de acordo com a Constituição, a fim de deixar claro que a União pode legislar sobre o tema, mas que o exercício desta competência deve sempre resguardar a autonomia dos demais entes. No seu entendimento, a possibilidade do chefe do Executivo Federal definir por decreto a essencialidade dos serviços públicos, sem observância da autonomia dos entes locais, afrontaria o princípio da separação dos poderes. Ficaram vencidos, neste ponto, o relator e o ministro Dias Toffoli, que entenderam que a liminar, nos termos em que foi deferida, era suficiente.

Observa-se, portanto que, no julgamento ocorrido no dia 15.04.2020, o STF de forma unânime, reiterou o entendimento do ministro Marco Aurélio Mello de que estados e municípios têm competência para adoção de atitudes que julgarem adequadas diante da crise sanitária, até mesmo porque existem impactos diferenciados em número de casos e mortes por Coronavírus em diversos estados da Federação, tendo sido mais afetados São Paulo, Rio de Janeiro, Ceará, Pernambuco, Amazonas e Distrito Federal, respectivamente.

O julgado abordado, concatena-se à problemática do acesso à saúde, consoante assevera Ingo Sarlet (2007, pág. 346), cumpre relembrar, mais uma vez, que a denegação dos serviços essenciais de saúde acaba- como sói acontecer- por se equiparar à aplicação de uma pena de morte para alguém cujo único crime foi o de não ter condições de obter com seus próprios recursos o atendimento necessário, tudo isto, habitualmente sem qualquer processo e, na maioria das vezes, sem possibilidade de defesa, isto sem falar na virtual ausência de responsabilização dos algozes, abrigados pelo anonimato dos poderes públicos. O que se pretende realçar, principalmente no caso do direito à saúde, o reconhecimento de um direito originário a prestações, no sentido de um direito subjetivo individual a prestações materiais (ainda que limitadas ao estritamente necessário para a proteção da vida humana), diretamente 


\section{MODULAÇÃO DE POLÍTICAS PÚBLICAS SANITÁRIAS DO PODER EXECUTIVO PELO SUPREMO \\ TRIBUNAL FEDERAL NO CONTEXTO DO QUADRO PANDÊMICO CAUSADO PELO CORONAVÍRUS \\ (COVID-19): ENFRENTAMENTO DE PARADOXOS}

deduzido da Constituição, constitui exigência inarredável de qualquer Estado (social ou não) que inclua nos seus valores essenciais a humanidade e a justiça.

O PSOL ajuizou no STF a ADPF $n^{\circ} .:$ 671/DF, Relator: Min. Ricardo Lewandowski, julgamento: 03/04/2020 com o pedido de que o poder público passe a regular a utilização dos leitos de UTIs, mesmo na rede privada, enquanto durar a pandemia do novo coronavírus. Para o partido, cabe ao SUS assumir integralmente a gestão de hospitais e profissionais de saúde públicos e privados, a fim de garantir o acesso igualitário aos serviços por meio de uma fila única de acesso. A legenda argumenta que o artigo $5^{\circ}$, inciso XXV da $\mathrm{CF} / 88$ prevê, em caso de perigo público iminente, que a propriedade particular pode ser usada por autoridade competente, mediante indenização posterior ao proprietário em caso de dano: "Em meio a uma pandemia e a essa crise, é justo que haja igualdade no acesso a esses leitos". Para o partido, compete a todos os entes da federação, nas suas respectivas esferas administrativas, intervir na propriedade privada, de maneira razoável e proporcional, a fim de concretizar o direito fundamental à saúde, à vida, à igualdade e à dignidade humana. $\mathrm{O}$ relator, em 03.04.2020, em decisão monocrática, indeferiu a aludida Ação sob o argumento: "De toda a sorte, mesmo considerada a grave crise sanitária pela qual passa o país, ainda é cedo para presumir a ocorrência de omissão dos gestores públicos, afigurando-se, no mínimo, prematuro concluir pelo descumprimento dos preceitos fundamentais." Ponderou o relator: "Por todos os ângulos que se examine a questão, forçoso é concluir que a presente ADPF não constitui meio processual hábil para acolher a pretensão nela veiculada, pois não cabe ao Supremo Tribunal Federal substituir os administradores públicos dos distintos entes federados na tomada de medidas de competência privativa destes, até porque não dispõe de instrumentos hábeis para sopesar os distintos desafios que cada um deles enfrenta no combate à Covid-19." $\mathrm{Na}$ decisão restou consignado o teor do $\S 1^{\circ}$ do art. $3^{\circ}$ da Lei $\mathrm{n}^{\circ} .: 13.979 / 2020$ ao dispor que as requisições e outras medidas de emergência para combater a Covid-19 “...somente poderão ser determinadas com base em evidências científicas e em análises sobre as informações estratégicas em saúde e deverão ser limitadas no tempo e no espaço ao mínimo indispensável à promoção e à preservação da saúde pública". Essa apreciação prevista na normatização de regência, conforme analisado pelo relator, compete exclusivamente às autoridades públicas, caso a caso, em face das situações concretas com as quais são defrontadas, inclusive à luz dos 
princípios da razoabilidade e proporcionalidade, sem prejuízo do posterior controle de constitucionalidade e legalidade por parte do Poder Judiciário.

Decerto, a decisão prolatada no âmbito da ADPF $n^{\circ}:$ : 671/DF atende à diferenciação traçada pelo Texto Constitucional entre o sistema único de saúde, a cargo da União, dos Estados, do Distrito Federal e dos Municípios (art.196 da CF/88) e a assistência à saúde permitida à iniciativa privada (art. 199 da CF/88), conforme assevera José Afonso da Silva (2006, pág. 832), responsável, pois, pelas ações e serviços de saúde é o Poder Público, falando a Constituição, neste caso, em ações e serviços públicos de saúde, para distinguir da assistência à saúde pela iniciativa privada, que ela também admite, e cujas instituições poderão participar complementarmente do sistema único de saúde, sendo vedadas a destinação de recursos públicos para auxílios ou subvenções às instituições privadas com fins lucrativos.

A atuação do Poder Executivo Federal no sentido de minimizar os impactos do coronavírus nas políticas públicas sanitárias tem sido revisada pelo Supremo Tribunal Federal a fim de garantir a efetividade do direito fundamental social à saúde, respeitando-se os sistemas de freios e contrapesos, uma vez reconhecida a insuficiência de serviços públicos em franco processo de exaurimento ante o agravamento do quadro pandêmico, sendo que o Poder Judiciário tem crescido em importância na instrumentalização do controle.

Normalmente, o direito à saúde é frequentemente demandado na esfera judicial, entretanto, tanto as lides individuais como as coletivas levam à desarticulação das políticas públicas do Estado, as quais são propostas e aprovadas pelos Poderes Legislativo e Executivo, valorizando o direito de poucos - os que têm acesso ao Judiciário - em detrimento da coletividade. No caso vertente, entretanto, ante a inércia ou falta de atendimento às recomendações da OMS e do próprio Ministério da Saúde, o STF assume o protagonismo no atendimento das medidas sanitárias mínimas, conforme as recomendações científicas na preservação da vida humana digna.

A partir da análise de decisões selecionadas proferidas pelo STF observa-se que a concretização do direito fundamental social à saúde no enfrentamento à Covid-19 tem se pautado por critérios de sensibilidade e racionalidade, ausentes na conduta do Presidente da República, respeitados os parâmetros de preservação do federalismo brasileiro, da democracia brasileira e dos freios e contrapesos, conforme propugnado pelo Texto Constitucional de 


\section{MODULAÇÃO DE POLÍTICAS PÚBLICAS SANITÁRIAS DO PODER EXECUTIVO PELO SUPREMO \\ TRIBUNAL FEDERAL NO CONTEXTO DO QUADRO PANDÊMICO CAUSADO PELO CORONAVÍRUS \\ (COVID-19): ENFRENTAMENTO DE PARADOXOS}

1988, havendo justo motivo objetivamente aferível.

Ante essa complexa e desafiadora realidade imposta pela Covid-19, Boaventura de Sousa Santos (2020) defende: "Só com uma nova articulação entre os processos políticos e os processos civilizatórios será possível começar a pensar uma sociedade em que a humanidade assuma uma posição mais humilde no planeta que habita".

$\mathrm{Na}$ presente crise humanitária, o Poder Executivo Federal assumiu uma conduta errática e tem mostrado mais falhas que outros governos na luta contra a pandemia. Verifica-se ocultação e falseamento de informações, desprestígio da comunidade científica, minimização dos efeitos potenciais deletérios da pandemia, manipulação da crise humanitária para a criação de crises políticas com modificação arbitrária de ministros e construção de um discurso falacioso, irresponsável e manipulador, como se saúde e economia fossem instâncias antitéticas. Sob o pretexto de salvar a economia, foram geradas políticas públicas sanitárias equivocadas, que geram a necessidade de revisão e o controle pelo Supremo Tribunal Federal.

O embate travado entre o Presidente da República e o Supremo Tribunal Federal enquadra-se no diagnóstico de Yuval Noah Harari (2020) conforme o qual, neste momento de crise, a batalha crucial está sendo travada dentro da própria humanidade. Se a epidemia criar mais desunião e desconfiança entre os seres humanos, o vírus terá obtido sua maior vitória. Quando os humanos brigam, os vírus se duplicam. Em troca, se a epidemia produzir uma maior cooperação mundial, essa será uma vitória não só contra o coronavírus, mas contra todos os futuros agentes patogênicos.

Até o início de maio de 2020, as políticas públicas sanitárias brasileiras parecem estar fracassando no combate aos efeitos deletérios do novo Coronavírus, uma vez que observa-se uma escala ascendente do número de casos comprovados e de mortos (o país ultrapassou os dados quantitativos do berço do vírus, a China), prognósticos negativos do Ministério da Saúde com a possibilidade concreta de milhares de mortes diárias causadas pelo quadro pandêmico. A realidade é dinâmica e os desafios são enormes na tentativa de reversão desse grave e doloroso quadro. A cada dia aparece um novo controle jurisdicional pelo STF de políticas públicas sanitárias do Poder Executivo Federal ante a ausência de diretrizes claras e congruentes na necessidade de combate à Covid-19.

No plano prospectivo, portanto, a humanidade se vê diante da encruzilhada prevista por Edgar Morin (2011, pág. 74), tantos problemas dramaticamente unidos fazem-nos 
pensar que o mundo não só está em crise; encontra-se em violento estado no qual se enfrentam as forças da morte e as forças da vida, que se pode chamar de "agonia". Ainda que solidários, os humanos permanecem inimigos uns dos outros, e o desencadeamento de ódios de raça, religião, ideologia conduz sempre a guerras, massacres, torturas, ódios, desprezo. Os processos são destruidores do mundo antigo, aqui, multimilenar, ali, multissecular. A humanidade não consegue gerar a Humanidade. Não sabemos ainda se se trata só da agonia de um velho mundo - prenúncio do novo nascimento- ou da agonia mortal. Nova consciência começa a surgir: a humanidade é conduzida para uma aventura desconhecida.

\section{Considerações Finais}

A postura intransigente, inconsequente e incongruente do Presidente da República reverberou na construção de intensos embates jurídicos, tendo como protagonista na solução das controvérsias, o Supremo Tribunal Federal (STF). As cizânias políticas geraram um intenso clima de insegurança no quadro federativo brasileiro, com decisões divergentes entre as decisões da União, dos estados e dos municípios.

O ministro relator Luis Roberto Barroso, no julgamento da Medida Cautelar ADPF n ${ }^{\circ} .: 669 / \mathrm{DF}$, vaticinou: “...na dúvida quanto à adoção de uma medida sanitária, deve prevalecer a escolha que ofereça proteção mais ampla à saúde.” Com esse entendimento, o magistrado concedeu pedido liminar para vedar a produção e circulação, por qualquer meio, de qualquer campanha publicitária promovida pelo Governo Federal que pregue: "O Brasil Não Pode Parar".

No julgamento da ADPF $n^{\circ} .: 568 / \mathrm{PR}$, o ministro Alexandre de Moraes, do Supremo Tribunal Federal (STF), determinou a imediata destinação de R\$ 1,6 bilhão ao Ministério da Saúde para custeio de ações de combate ao coronavírus (Covid-19). Conforme diagnóstico do magistrado: "O desafio que a situação atual coloca à sociedade brasileira e às autoridades públicas é da mais elevada gravidade, e não pode ser minimizado. A pandemia de COVID-19 (Coronavírus) é uma ameaça real e iminente, que irá extenuar a capacidade operacional do sistema público de saúde, com consequências desastrosas para a população, caso não sejam adotadas medidas de efeito imediato.” Em julgamento ocorrido no dia 15.04.2020, o STF de forma unânime, reiterou o entendimento do ministro Marco Aurélio Mello de que estados e municípios têm competência para adoção de atitudes que julgarem adequadas diante da crise sanitária, até mesmo porque existem impactos diferenciados em 


\section{MODULAÇÃO DE POLÍTICAS PÚBLICAS SANITÁRIAS DO PODER EXECUTIVO PELO SUPREMO TRIBUNAL FEDERAL NO CONTEXTO DO QUADRO PANDÊMICO CAUSADO PELO CORONAVÍRUS (COVID-19): ENFRENTAMENTO DE PARADOXOS}

número de casos e mortes por Coronavírus em diversos estados da Federação na Ação Direta de Inconstitucionalidade (ADI) $\mathrm{n}^{\circ} .: 6341$ para explicitar que as medidas adotadas pelo Governo Federal na Medida Provisória (MP) $n^{\circ} .:$ 926/2020 para o enfrentamento do novo coronavírus não afastam a competência concorrente nem a tomada de providências normativas e administrativas pelos estados, pelo Distrito Federal e pelos municípios.

Por outro lado, o relator da ADPF $\mathrm{n}^{\circ} .: 671$, ministro Ricardo Lewandowski, em 03.04.2020, em decisão monocrática, indeferiu a aludida Ação sob o argumento de que não cabe ao Supremo Tribunal Federal substituir os administradores públicos dos distintos entes federados na tomada de medidas de competência privativa destes, até porque não dispõe de instrumentos hábeis para sopesar os distintos desafios que cada um deles enfrenta no combate à Covid-19.

A atuação do Poder Executivo Federal no sentido de minimizar os impactos do coronavírus nas políticas públicas sanitárias tem sido revisada pelo STF a fim de garantir a efetividade do direito fundamental social à saúde, respeitando-se os sistemas de freios e contrapesos, uma vez reconhecida a insuficiência de serviços públicos em franco processo de exaurimento ante o agravamento do quadro pandêmico, sendo que o Poder Judiciário tem crescido em importância na instrumentalização do controle.

A partir da análise de decisões selecionadas proferidas pelo STF observa-se que a concretização do direito fundamental social à saúde no enfrentamento à Covid-19 tem se pautado por critérios de sensibilidade e racionalidade, ausentes na conduta do Presidente da República, respeitados os parâmetros de preservação do federalismo brasileiro, da democracia brasileira e dos freios e contrapesos, conforme propugnado pelo Texto Constitucional de 1988, havendo justo motivo objetivamente aferível.

\section{Referências Bibliográficas}

BARCELlOS, Ana Paula de. O Direito a Prestação de Saúde: complexidades, mínimo existencial e o valor das abordagens coletiva e abstrata. In: Direitos Sociais: fundamentos, judicialização e direitos sociais em espécie. SARMENTO, Daniel; SOUZA NETO, Cláudio Pereira de (Coord.), Rio de Janeiro: Lumen Juris, 2010.

BARROSO, Luís Roberto. Da falta de efetividade à judicialização excessiva: direito à saúde, fornecimento gratuito de medicamentos e parâmetros para a atuação judicial. R. Jur. UNIJUS, Uberaba-MG, V.11, n. 15, p.13-38 novembro, 2008. 
BONAVIDES, Paulo. Do Estado Liberal ao Estado Social.7ª - edição. São Paulo: Malheiros, 2004.

CANOTILHO, José Joaquim Gomes. Direito Constitucional e Teoria da Constituição. $7^{\text {a }}$ edição. Coimbra: Almedina, 2006.

FERRAJOLI, Luigi. Garantismo. Debate sobre el derecho y la democracia. Traducción: Andrea Greppi. Segunda edición. Madrid: Editorial Trotta, 2009.

GONZÁLEZ, Enrique. El Derecho a la salud. In: ABRAMOVICH, Víctor; AÑON, María José; COURTIS, Christian (Org.). Derechos sociales. Instrucciones de uso. Mexico: Fontamara, 2006.

HARARI, Yuval Noah. Na batalha contra o coronavírus, faltam líderes à humanidade. Tradução: Odorico Leal. São Paulo: Companhia das Letras, 2020.

MARQUES JÚNIOR, William Paiva. Análise da experiência brasileira na primazia do Poder Judiciário na execução de políticas públicas de acesso ao direito social à saúde. Revista Latino-Americana de Estudos Constitucionais, v. 17, p. 459-478, 2015.

MATTEUCCI, Nicola. Direitos Humanos. In: BOBBIO, Norberto; MATTEUCCI, Nicola; PASQUINO, Gianfranco (orgs.). Dicionário de Política. Volume I. Tradução: João Ferreira et. all. Brasília: Editora da Universidade de Brasília, 1998.

Ministério da Saúde. Painel coronavírus. Disponível em: < https://covid.saude.gov.br/>. Acesso em: 01.05.2020.

MORIN, Edgar. Os sete saberes necessários à educação do futuro. Tradução: Catarina Eleonora F. da Silva e Jeanne Sawaya. 2a - edição. 6a - reimpressão São Paulo: Cortez, 2011.

OPAS (Organização Pan-Americana da Saúde). Folha informativa - COVID-19 (doença causada pelo novo coronavírus). Disponível em: < https://www.paho.org/bra/index.php?option=com_content\&view=article\&id=6101: covid19\&I temid=875 $>$. Acesso em: 21.04.2020.

PIOVESAN, Flávia. Temas de Direitos Humanos. 9ª - edição. São Paulo: Saraiva, 2016. RICUPERO, Rubens. A diplomacia na construção do Brasil: 1750-2016. $1^{\text {a }}$ - edição. Rio de Janeiro: Versal Editores, 2017.

SANTOS, Boaventura de Sousa. A cruel pedagogia do vírus. São Paulo: Boitempo, 2020.

SANTOS, Boaventura de Sousa. Para uma revolução democrática da justiça. $3^{\text {a }}$ - edição. São Paulo: Cortez, 2011. 
SARLET, Ingo Wolfgang. A eficácia dos direitos fundamentais. $7^{\text {a }}$ - edição. Porto Alegre: Livraria do Advogado Editora, 2007.

SARLET, Ingo Wolfgang. Dignidade da Pessoa Humana e Direitos Fundamentais na Constituição de 1988. $4^{\text {a }}$ - edição. Porto Alegre: Livraria do Advogado, 2006.

SANDEL, Michael J. Justiça. O que é fazer a coisa certa. Tradução: Heloísa Matias e Maria Alice Máximo. 9ª - edição. Rio de Janeiro: Civilização Brasileira, 2012.

SEN, Amartya. A ideia de justiça. Tradução: Denise Bottmann e Ricardo Doninelli Mendes.

São Paulo: Companhia das Letras, 2011.

SEN, Amartya. Desenvolvimento como liberdade. Tradução: Laura Teixeira Mota. São Paulo: Companhia das Letras, 2010.

SILVA, José Afonso da. Curso de Direito Constitucional Positivo. 27 - edição. São Paulo: Malheiros. 2006. 